\title{
Promising Anticancer Effect of Aurisin A Against the Human Lung Cancer A549 Cell Line
}

\author{
Parichart Boueroy ${ }^{1,2}$, Thidarut Boonmars ${ }^{2,3 *}$, Somdej Kanokmedhakul ${ }^{4}$, Sorujsiri \\ Chareonsudjai $^{5}$, Ratsami Lekphrom ${ }^{4}$, Suphachira Srichangwang ${ }^{6}$
}

\begin{abstract}
Objective: To investigate the anticancer effect of aurisin A and the underlying mechanisms of its action on the human lung cancer A549 cell line. Methods: Cell viability was determined by sulforhodamine B (SRB) assay, while cell cycle distribution and apoptosis were measured by flow cytometry. The molecular underlying mechanisms of anti-cancer properties of aurisin A was determined by western blot analysis. Results: Aurisin A exerts its anticancer effects by inhibiting cell growth $(\mathrm{p}<0.001)$, increasing the proportion of cells at the $\mathrm{G} 0 / \mathrm{G} 1 \mathrm{phase}(\mathrm{p}<0.001)$, and decreasing the expression of cyclin D $(p<0.05)$ and cyclin-dependent kinase $4(\mathrm{Cdk}-4)(\mathrm{p}<0.001)$. Nuclear morphological changes were observed in aurisin A-treated cells, demonstrated by a dose-dependent increase in the number of apoptosis cells $(\mathrm{p}<0.001)$. After aurisin A treatment, B-cell lymphoma $2(\mathrm{Bcl}-2)$ was down-regulated $(\mathrm{p}<0.05)$, cleaved caspase-3 was up-regulated $(p<0.05)$. In addition, aurisin A inhibits migration of cancer cells in a dose-dependent manner $(p<0.001)$ and decreases the expression of epidermal growth factor receptor $(E G F R)(p<0.05)$ and phosphorylated p38 (pp38) $(p<0.05)$. Conclusion: These results indicated that in-vitro treatment of aurisin A against this human lung cancer cell line inhibits cell proliferation and migration, and induces apoptosis and cell-cycle arrest. Aurisin A is a promising anticancer agent for use against human lung cancer.
\end{abstract}

Keywords: Lung anticancer- aurisin A- anti-migration- cell cycle arrest- apoptosis

Asian Pac J Cancer Prev, 21 (1), 49-54

\section{Introduction}

Lung cancer is one of the most common cancers in the world and an increasing cause of death in the United States of America (Brognard et al., 2001; Khuri and Cohen, 2004; Siegel et al., 2003; Govindan et al., 2012). Lung cancer has a high mortality rate because of its resistance to some current chemotherapeutic agents and difficulty of diagnosis (Brognard et al., 2001; Balsara et al., 2004; Hirsch et al., 2003). It is estimated about 1.8 million new cancer cases ( $13 \%$ of total cancer diagnoses) and more than 1 million related deaths per year (Torre et al., 2012). In the worldwide, lung cancer is the most common cause of death in men more than women (Pakzad et al., 2015). In addition, this cancer has a high incidence of recurrence. Non-small cell lung cancer (NSCLC) is the most common type of lung cancer, constituting approximately 75 $85 \%$ of all cases. The usual chemotherapeutic agent for treatment of advanced NSCLC is the highly toxic platinum-based cisplatin. However, patients given this treatment have a low survival rate (Khuri et al., 2001; Li et al., 2004; Molina et al., 2006; Raez and Lilenbaum, 2004). Therefore, there is an urgent need for new therapeutic agents to treat lung cancer. The induction of apoptosis is a targeted strategy in effective drug design for cancer treatment, including human lung carcinoma (Singhal et al., 2005). Previously, aurisin A was shown to inhibit the growth of human small-cell lung cancer (NCI-H187) and cholangiocarcinoma (KKU-100, KKU-139, KKU-156, KKU-213, and KKU-214) cell lines. Moreover, aurisin A has various biological properties such as anti-malarial (Plasmodium falciparum) and anti-bacterial activities (Mycobacterium tuberculosis) (Kanokmedhakul et al., 2012).

\section{Materials and Methods}

Cell culture and plant material

The human lung adenocarcinoma cell line (A549) (CCL-185), used as a model, was purchased from the

${ }^{1}$ Faculty of Public Health, Kasetsart University Chalermphrakiat Sakon Nakhon Province Campus, Sakon Nakhon, ${ }^{2}$ Department of Parasitology, ${ }^{3}$ Cholangiocarcinoma Research Institute, Faculty of Medicine, ${ }^{4}$ Natural Products Research Unit, Department of Chemistry and Center of Excellence for Innovation in Chemistry, Faculty of Science, ${ }^{5}$ Department of Microbiology, Faculty of Medicine, ${ }^{6}$ Research Administration Division, Khon Kaen University, Khon Kaen, Thailand. *For Correspondence: bthida@kku.ac.th 
American Type Culture Collection, MD, USA. Cancer cells were cultured in RPMI 1640 (Gibco; Thermo Fisher Scientific, Inc.) supplemented with 10\% FBS, 100 units/ $\mathrm{ml}$ of penicillin and $100 \mu \mathrm{g} / \mathrm{ml}$ streptomycin (Gibco BRL) at $37^{\circ} \mathrm{C}$ in $5 \% \mathrm{CO}_{2}$ humidified atmosphere. Aurisin $\mathrm{A}$ has been extracted from culture medium of the luminescent mushroom Neonothopanus nambi $\mathrm{PW} 1$, and its molecular formula $\left(\mathrm{C}_{30} \mathrm{H}_{36} \mathrm{O}_{9}\right)$ was deduced from HRESITOFMS (m/z 540.2257) (Kanokmedhakul et al., 2012). The culture liquid of PW1 (2.025 L) was extracted with EtOAc (2.5 L) yielded $2.1 \mathrm{~g}$ of yellow crystals of aurisin A. Yellow crystals of aurisin A were obtained after crystallization and slow evaporation from EtOAc follow as previous study (Kanokmedhakul et al., 2012). It was decomposed at $221.9^{\circ} \mathrm{C}$ and has a specific rotation, $[\alpha]_{\mathrm{D}}{ }^{26}+701.3$ (c $0.1, \mathrm{CHCl}_{3}$ ). Aurisin A is soluble in dimethyl sulfoxide (DMSO) at $25 \mathrm{mg} / \mathrm{mL}$ and in $95 \%$ ethanol (EtOH) at 12.5 $\mathrm{mg} / \mathrm{mL}$. UV absorption at $\lambda_{\max } 331 \mathrm{~nm}(\log \varepsilon 4.25)$ and 268 ( $\log \varepsilon$ 4.23) (Kanokmedhakul et al., 2012). Aurisin A was dissolved in DMSO to a concentration of $16 \mathrm{mM}$ and further diluted to appropriate concentrations in the experiments. 5-FU (Boryung Pharmaceutic Co., Ltd. Korea) was aliquoted and kept at $4^{\circ} \mathrm{C}$.

\section{Cell viability assay}

The effect of aurisin A on cell viability of human adenocarcinoma (A549) cell lines was determined using a sulforhodamine B (SRB) assay. Briefly, human adenocarcinoma (A549) cells were seeded into 96-well plates at $37^{\circ} \mathrm{C}$. Cells were treated with aurisin $\mathrm{A}(0,1,2,4$, $8,16,32 \mu \mathrm{M}$ ) for 24,48 or $72 \mathrm{~h}$. After the treatment, cells were fixed, aspirated and incubated with SRB dye (Sigma Aldrich, Germany) for $30 \mathrm{~min}$ at room temperature. The protein-bound dye was solubilized by Tris base solution (10 mM, pH 10) (Sigma). The optical density (OD) was determined at $540 \mathrm{~nm}$ using a micro plate reader (ELISA Reader, Sunrise). The IC50 value was calculated from concentration-effect curves after linear regression analysis.

\section{Wound migration assay}

The human lung cancer A549 cells were seeded in 6-well plates and grown to $80-90 \%$ confluence. Monolayers of cells were wounded by scratching with a 1 $\mathrm{mL}$ plastic pipette and then rinsed with phosphate-buffered saline (PBS) to remove cell debris. Cells were incubated in medium containing $1 \%$ fetal bovine serum (FBS) with or without aurisin $\mathrm{A}(0,6.25,10.43$ and $16.68 \mu \mathrm{M})$ for 24 or $48 \mathrm{~h}$. The extent of the wound closure was monitored by microscopy and digitally photographed. The area of the wound was measured.

\section{Cell-cycle analysis \\ Human lung adenocarcinoma}

(A549) cells $\left(1 \times 10^{5}\right.$ cells $/$ well $)$ were seeded in 6-well plates for $24 \mathrm{~h}$ and then treated with aurisin $\mathrm{A}(0,6.25$, 10.43 and $16.68 \mu \mathrm{M})$ and 5 -FU $(50 \mu \mathrm{g} / \mathrm{ml})$. After $24 \mathrm{~h}$, cells were harvested, washed, and fixed overnight in $70 \%$ ethanol at $4{ }^{\circ} \mathrm{C}$, and incubated at room temperature for $30 \mathrm{~min}$ in the dark with RNase A (final concentration $2 \mu \mathrm{g} / \mathrm{mL}$ ) and propidium iodide (PI) (final concentration
$2.4 \mu \mathrm{g} / \mathrm{mL}$ ). The cell-cycle distribution was examined using a FACSCanto ${ }^{\mathrm{TM}}$ II flow cytometer (BD Biosciences, San Jose, CA, USA) and the data were analyzed using FACSDiva $^{\mathrm{TM}}$ software (BD Biosciences).

\section{Acridine orange/Ethidium bromide (AO/EB)}

Human lung adenocarcinoma (A549) cells were treated with various concentrations of aurisin A $(0,6.25,10.43$ and $16.68 \mu \mathrm{M}$ ) for $24 \mathrm{~h}$. Cells were stained with $14 \mu \mathrm{l}$ of $100 \mu \mathrm{g} / \mathrm{ml}$ of AO/EB mixture. Apoptotic cells with condensed or fragmented chromatin were observed with a confocal microscope. The percentage of apoptotic cells which are condensed chromatin or fragmented chromatin was calculated from 500 counted cells (Hahnvajanawong C et al., 2004).

Apoptotic cell death detection assay via flow cytometry

The effect of aurisin A on apoptosis induction in A549 cells was determined using an annexin-V-FLUOS staining kit (Roche Diagnostics, Penzberg, Germany). A549 cells $\left(1 \times 10^{5}\right.$ cells $/$ well $)$ were treated with aurisin $\mathrm{A}(0,6.25,10.43$ and $16.68 \mu \mathrm{M})$ and 5 -FU $(50 \mu \mathrm{g} / \mathrm{ml})$ for $24 \mathrm{~h}$. Floating and adherent cells were harvested by trypsinization, washed, and centrifuged to collect the supernatant. Cells were stained with annexin V-FITC (recombinant annexin $\mathrm{V}$ protein conjugated to green fluorescent FITC dye) and PI for $10-15 \mathrm{~min}$ at room temperature in the dark. The stained cells were then analyzed by flow cytometry.

\section{Protein extraction and western blot analysis}

The human lung adenocarcinoma (A549) cell line was cultured in $10 \mathrm{~cm}$-diameter dishes (Costar ${ }^{\circledR}$; Corning, Corning, NY, USA $)$ and incubated with aurisin $\mathrm{A}(0,6.25$, $10.43,16.68 \mu \mathrm{M})$ for $24 \mathrm{~h}$. Harvested cells were lysed with ice-cold radioimmunoprecipitation assay (RIPA) buffer (50 mM Tris- $\mathrm{HCl}$ [pH 7.5], $150 \mathrm{mM} \mathrm{NaCl}, 0.5 \%$ Nonidet P-40 detergent, $1 \mathrm{mM}$ EDTA, $1 \mathrm{mM}$ dithiothreitol, $0.5 \%$ deoxycholate and $0.1 \%$ sodium dodecyl sulfate). The cell lysate was homogenized and clarified by centrifugation at $13,000 \mathrm{rpm}$ for $30 \mathrm{~min}$ at $4^{\circ} \mathrm{C}$. The protein concentration in the total cell lysate was determined by the Bradford method (Bradford, 1976). Cell lysates (5 $\mu \mathrm{g}$ of protein per lane) were fractionated by SDS-polyacrylamide gel electrophoresis (12\% SDS-PAGE). The proteins were transferred onto a nitrocellulose membrane. The membrane was blocked and probed with primary antibody agents EGFR, pp38, Cyclin D, Cdk-4, Bax, Bcl-2, cleaved caspase- 3 and $\beta$-actin, and then incubated with horseradish peroxidase-conjugated secondary antibody. The bound secondary antibodies on the nitrocellulose membrane were visualized using an enhanced chemiluminescence reagent (Pierce ECL; Thermo Fisher Scientific, Waltham, MA, USA), quantified by densitometry (ImageQuant LAS 4000; GE Healthcare, Chicago, IL, USA) and analyzed using the Scion Image program (Scion Corp., Frederick, MD, USA). The results were expressed as the relative density of protein normalized to $\beta$-actin.

\section{Statistical analysis}

Data are represented as mean $\pm \mathrm{SD}$ of three independent 
experiments. Significant differences between the groups were analyzed by Student's t-test using SPSS statistical software, version 16.0 (SPSS, Chicago, IL, USA). Statistical significance is indicated by $* p<0.05, * * p<0.01$ or $* * * \mathrm{p}<0.001$.

\section{Results}

Aurisin A inhibits cancer cell proliferation in human lung cancer A549 cells

The anticancer properties of aurisin A were determined by SRB assay. As shown in Figure 1, the human lung cancer cell line A549 was treated with aurisin A at various concentrations for 24, 48 or $72 \mathrm{~h}$. Aurisin A was found to inhibit A549 viability in a time-dependent manner with IC50 $10.43 \pm 1.26,10.60 \pm 0.69,9.2 \pm 0.87$, respectively.

\section{Aurisin A inhibited cancer cell migration in human lung cancer A549 cells}

The effect of aurisin A on cell migration of A459 cells is shown in Figure 2. Aurisin A significantly inhibited cell migration into the wounded area in a dose- and time-dependent manner in all experimental dose. The percentage of migration area after treatment with aurisin $\mathrm{A}(16.68 \mu \mathrm{M})$ at 24 and $48 \mathrm{~h}$ was $30.25 \pm 6.79 \%$ and 7.30 $\pm 0.72 \%$, respectively, compared with the control group $100 \pm 0.0 \%$ (Figure 2).

Aurisin A-induced cell-cycle arrest in the G0/G1 phase

The effect of aurisin A on cell-cycle distribution of the A549 cell line was determined by flow cytometry analysis. Aurisin A treatment significantly increased the population in the $\mathrm{G} 0 / \mathrm{G} 1$ phase from $74.7 \pm 1.97 \%$ to $87.23 \pm 0.64$ $\%$ as compared to controls (Figure 3 ). The percentage of cells significantly decreased in the $\mathrm{S}$ phase (from 17.17 $\pm 2.6 \%$ to $9.53 \pm 0.75 \%$ ) and $\mathrm{G} 2 / \mathrm{M}$ phase (from $7.43 \pm$ $1.17 \%$ to $2.6 \pm 0.2 \%$ ), as shown in Figure 3. Fluorouracil (5-FU), the positive control, also significantly increased the proportion of cells in the G0/G1 phase from $74.7 \pm$ $1.97 \%$ to $81.07 \pm 1.66 \%$ as compared to negative controls (Figure 3).

Aurisin A-induced apoptosis in human lung cancer A549 cells

The results of $\mathrm{AO} / \mathrm{EB}$ staining were observed under a confocal microscope. Aurisin A-induced nuclear morphological changes included nuclear condensation and DNA fragmentation, as shown by white arrowheads in Figure 4A. Late apoptotic or necrotic cells were observed in the aurisin A-treated group, as shown stained red in Figure 4A. The percentage of apoptotic cells was significantly increased in aurisin A treated cells compared to untreated cells (Figure 4B). Consistent with flow cytometry analysis in annexin V/PI staining, treatment with aurisin A significantly increased the percentage of apoptotic cells from $13.2 \pm 2.07 \%$ to $23.93 \pm 2.41 \%$ as compared to controls (Figure 5). Also, treatment with 5-FU significantly increased the proportion of apoptotic cells (from $13.2 \pm 2.07$ to $24.3 \pm 1.32$ ) as shown in Figure 5.

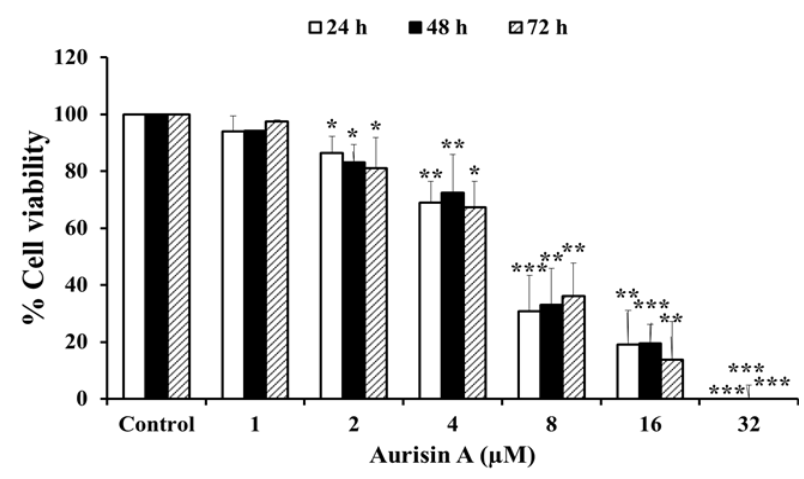

Figure 1. Growth Inhibitory Effect of Aurisin A on Human Lung Carcinoma (A549) Cells. A549 cells were treated with aurisin $\mathrm{A}(0,1,2,4,8,16,32 \mu \mathrm{M})$ on 24 , 48 , and $72 \mathrm{~h}$. Viability of cells was determined by SRB assay. Each value represents the mean $\pm \mathrm{SD}$ of three independent experiments. ${ }^{*} p<0.05, * * p<0.01, * * * p$ $<0.001$

A

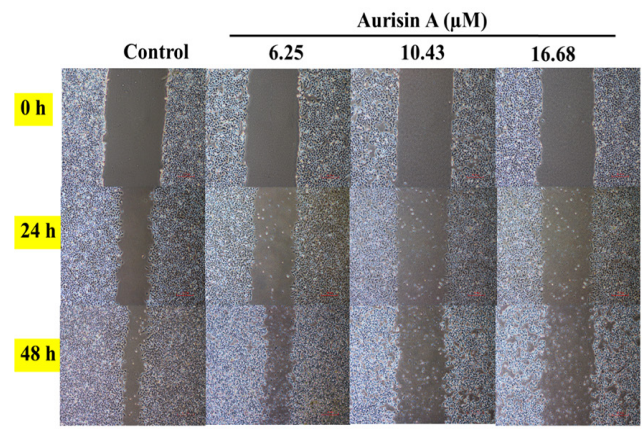

B

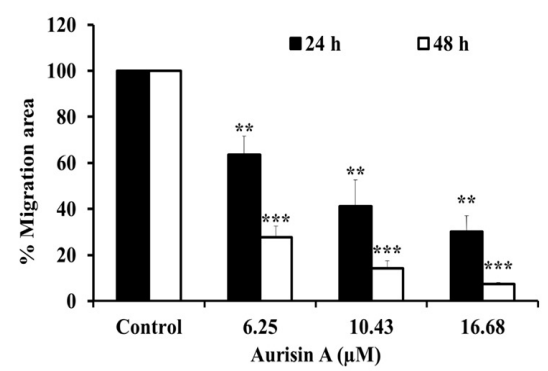

Figure 2. Anti-Migration Effect of Aurisin A on A549 Cells. Cells were seeded in 6-well plate. A Monolayer of cells were wounded and treated with aurisin A for 24 and $48 \mathrm{~h}$. The wound area was determined by a phase-contrast microscope at $10 \times$ magnifications. The closure of gap distance was examined by (A) photographs and (B) calculated the percentage of migration area. $* * p<0.01$, $* * * \mathrm{p}<0.001$

Effect of aurisin A on the expression of proteins associated with cell migration, cell cycle and apoptosis

As shown in Figure 6, the expression of proteins regulating cell migration (epidermal growth factor receptor (EGFR) and phosphorylated p38) was downregulated after treatment with aurisin A. In keeping with the ability of aurisin A to induce cell-cycle arrest at the G0/G1 phase, the expression of cell cycle-regulated proteins cyclin D and Cdk-4 was significantly decreased as compared to controls (Figure 6). Similarly, the expression of anti-apoptotic protein Bcl-2 was significantly decreased and cleaved

Asian Pacific Journal of Cancer Prevention, Vol 21 

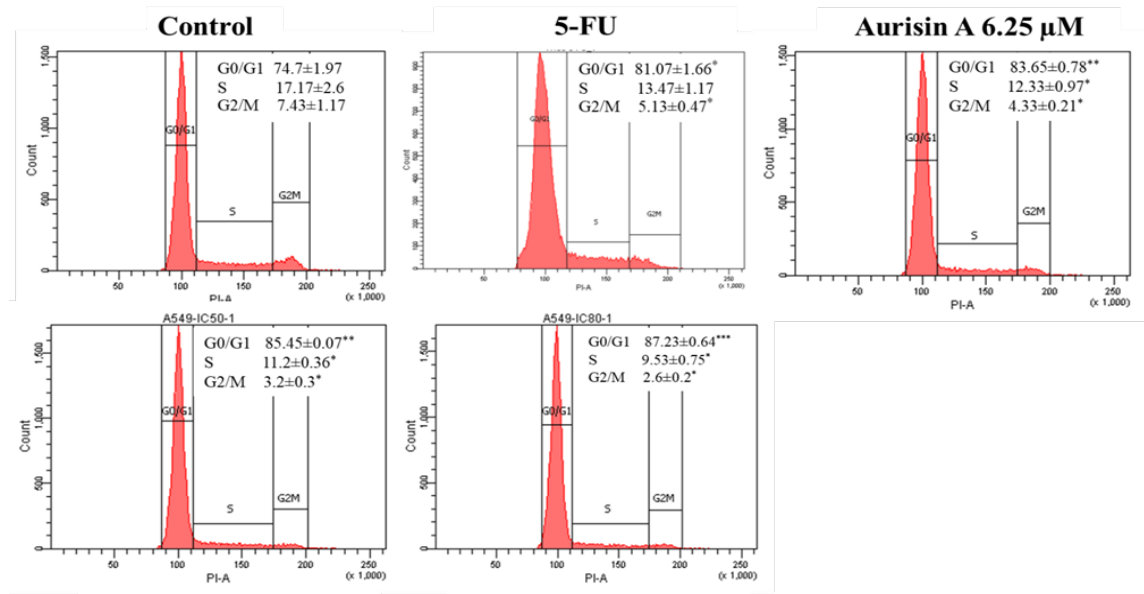

Aurisin A $16.68 \mu \mathrm{M}$

Figure 3. Cell Cycle Arrest in Aurisin A-Treated A549 Cells. A549 cells were treated with aurisin A and 5-FU for $24 \mathrm{~h}$ and stained nuclei with PI and analyzed by flow cytometry. The DNA content of cells was determined in three independent experiment. *p $<0.05, * * \mathrm{p}<0.01, * * * \mathrm{p}<0.001$

A

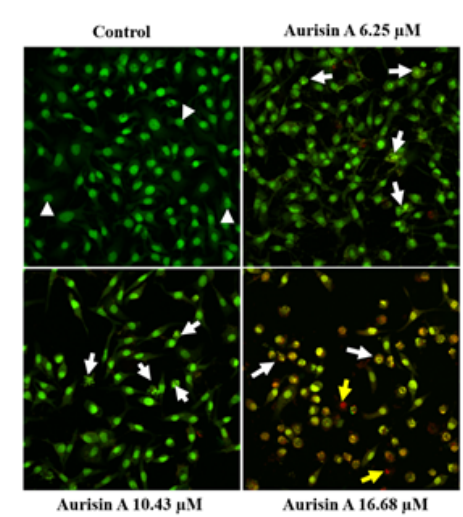

B

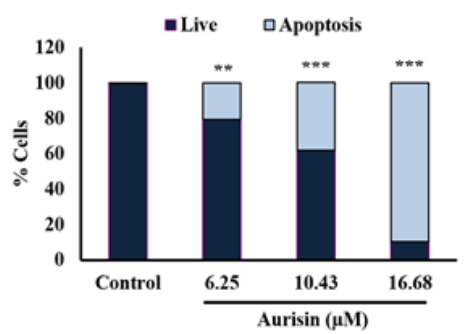

Figure 4. Nuclear Morphological Change of Aurisin A on A549 Cells. A549 cells were treated with aurisin A for 24 hr. (A) Cells were stained acridine orange/ethidium bromide and observed under a confocal microscope (magnification, $\mathrm{x} 20$ ). (B) Percentage of live and apoptotic cells in A549 cells treated with aurisin A. Normal cells were shown in arrow head, indicating normal with green homogeneous of the nucleus. Early apoptosis cells were shown in white arrow, indicating nuclear condensation and fragmentation. Late apoptosis cells were shown in yellow arrow, indicating cells that lose membrane integrity.

caspase-3 was up-regulated, but the pro-apoptotic protein Bax was not affected (Figure 6).

\section{Discussion}

This present study shows that aurisin A has promise as an anti-cancer agent, as evidenced by; i) inhibited cell proliferation and cancer cell migration (decreased EGFR and pp38 expression), ii) induced apoptosis (up-regulated caspase-3) and iii) cell cycle arrest at the G0/G1 phase with decreased expression of the proteins cyclin $\mathrm{D}$ and Cdk-4.

Previous studies reported about natural active compound can induce apoptosis and cell cycle arrest in human lung cancer (Peng et al., 2016; Su et al., 2014). Dysregulation of cell proliferation, together with inhibition of the apoptosis pathway, is associated with tumorigenesis (Evan and Vousden, 2001). Induction of apoptosis in the tumor is a desired result of treatment with chemotherapeutic agents and radiation. The apoptosis pathway has several cellular and molecular biological features including cell shrinkage, nuclear and chromatin condensation, externalization of phosphatidyl serine (PS) and activation of caspase (Martin et al., 1995; Salvesen and Dixit, 1997; Goldar et al., 2015). We determined morphological changes by observation of cells stained with $\mathrm{AO} / \mathrm{EB}$, which allowed us to see condensation and fragmentation of DNA in A549 cells after treatment with aurisin A. Central regulators in the apoptotic family either inhibit (Bcl 2 and $\mathrm{Bcl}$ extra large) or promote (Bax and Bak) programmed cell death (Daniel and Korsmeyer, 2004; Liang et al., 2011; Hata et al., 2015). The balance between the levels of pro- and anti-apoptotic proteins is important for cell survival or programmed cell death (Peng et al., 2016). In this study, we found that aurisin A-mediated induction of apoptosis in A549 cells was associated with decreased expression of $\mathrm{Bcl}-2$.

Activation of caspases is important for induction of apoptosis (Nicholson and Thornberry, 1997). The caspase family is divided into initiator and activator caspases. Initiator caspases, such as caspase-1, -2, -8, -9, and -10, initiate a proteolytic cascade while activated caspases, such as caspase- $3,-6$, and -7 , are associated with cleavage of specific intracellular substrates (focal adhesion kinase, 
A
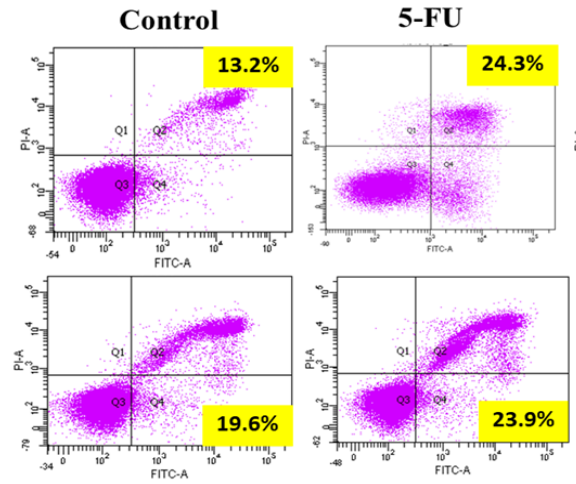

Aurisin A 10.43 $\mu$ M Aurisin A $16.68 \mu M$

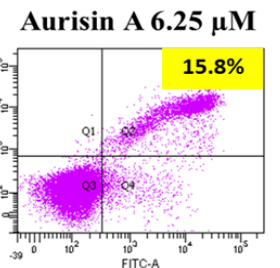

B

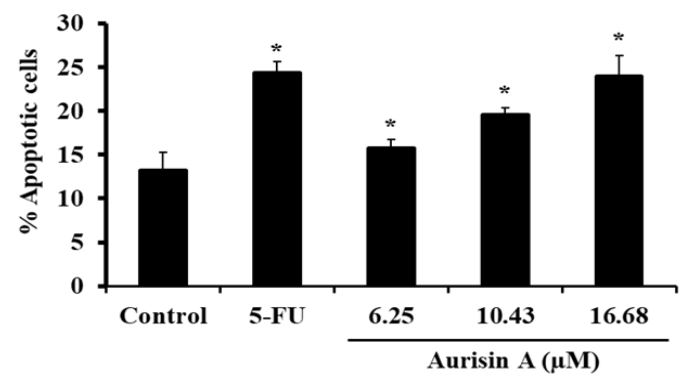

Figure 5. Apoptotic Effect of Aurisin A on A549 Cells. A549 cells were treated with aurisin A and 5-FU for 24 h. Cells were stained with Annexin V/PI and analyzed by flow cytometry. (B) The percentage of apoptotic cells was quantified by three independent experiment. ${ }^{*} \mathrm{p}<0.05$

poly-ADP-ribose polymerase) (Salvesen and Dixit, 1997; Nicholson and Thornberry, 1997; Alnemri et al., 1996;

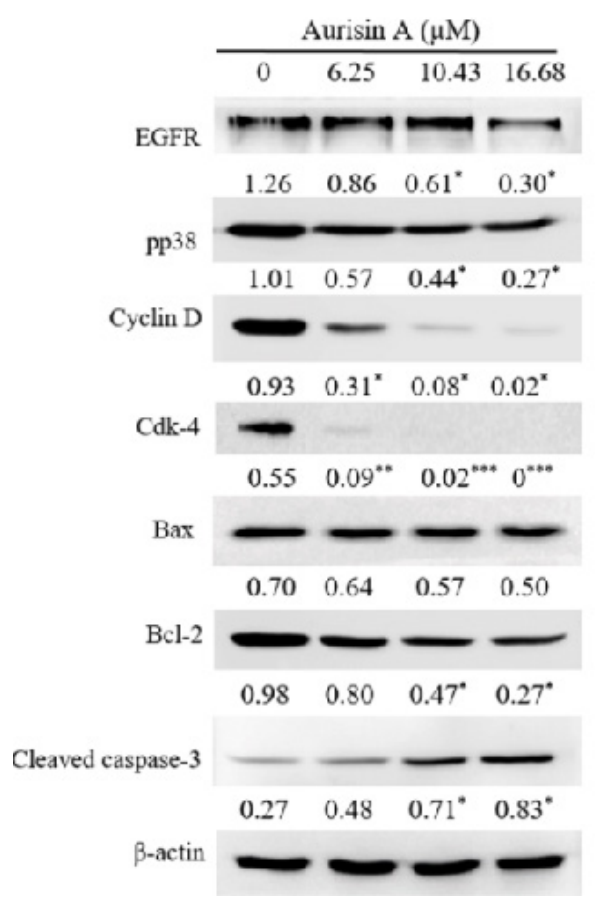

Figure 6. Changed the Protein Expression Related to Cell Migration, G0/G1 Arrested, and Apoptosis in A549 Cells. A549 cells were treated with aurisin A for $24 \mathrm{~h}$. The expression of cell migration-related molecules, EGFR and pp38, cell cycle arrest-related molecules, Cyclin D and Cdk-4 and apoptosis-related molecules Bax, Bcl-2 and Cleaved caspase-3 were normalized relative to $\beta$-actin. Data are presented as mean $\pm \mathrm{SD}$ of three separate experiments. ${ }^{*} \mathrm{p}<0.05, * * \mathrm{p}<0.01, * * * \mathrm{p}$ $<0.001$
Hu et al., 2013). We found that aurisin A can induce the externalization of PS and activate cleaved caspase-3. Caspase-3 is essential for DNA fragmentation leading to morphological changes associated with apoptosis (Janicke et al., 1998), changes which were evident in A549 cells treated with aurisin A.

Inhibition of cancer cell migration is one of the therapeutic targets of effective anti-cancer drugs. Mitogen-activated protein kinases (MAPK) fall into three subfamilies; extracellular signal-regulated kinases (ERK), Jun $\mathrm{NH}_{2}$-terminal kinases (JNK), and p38 kinases. These pathways are important in tumor progression and metastasis (Reddy et al., 2003). The EGFR signal-transduction pathway is an important target for anticancer drugs. EGFR is a receptor of tyrosine kinase that is overexpressed in various types of cancer such, as breast, head and neck, ovarian and non-small cell lung cancer (Salomon et al., 1996; Huang and Fu, 2015). Recognition of EGFR plays an important role in inflammation, cell survival, cell adhesion, cell motility, invasion and angiogenesis (Woodburn, 1999). Verbeek et al., (1998) reported that overexpression of EGFR can induce cell migration in human breast cancer. We found that aurisin A can inhibit the migration of A549 cells by decreasing the expression of migration regulating protein pp38 and EGFR.

In conclusions, we conclude that aurisin A exerts cytotoxic effects against human lung carcinoma. This effect is associated with the inhibition of cancer cell migration, and induction of cell-cycle arrest and apoptosis in A549 cells. At the molecular level, aurisin A causes changes in the expression of migration-related proteins EGFR and pp38, G0/G1 phrase-related proteins cyclin D 
and $\mathrm{Cdk}-4$, and apoptosis-regulated proteins Bcl-2 and cleaved caspase-3. These results indicate that aurisin A has potential as a drug treatment for human lung carcinoma.

\section{Acknowledgments}

This study was supported by the Cholangiocarcinoma Screening and Care Program (CASCAP), Thailand Grand Challenges; Fluke-Free Thailand, TRF Senior Research Scholar (grant no. RTA5880001) and invitation research (IN61125). This research was supported by the Post-Doctoral Program for Research Affairs and Graduate School, Khon Kaen University (no. 58441). We would like to acknowledge Prof. Dr. David Blair, for editing the MS via Publication Clinic KKU, Thailand.

\section{Conflict of interests}

No competing of interests exist.

\section{References}

Alnemri ES, Livingston DJ, Nicholson DW, et al (1996). Human ICE/CED-3 protease Nomenclature. Cell, 87, 171.

Balsara BR, Pei J, Mitsuuchi Y, et al (2004). Frequent activation of AKT in non-small cell lung Carcinomas and preneoplastic bronchial lesions. Carcinogenesis, 25, 2053-9.

Bradford MM (1976). A rapid and sensitive method for the quantitation of microgram quantities of protein utilizing the principle of protein-dye binding. Anal Biochem, 72, 248-54.

Brognard J, Clark AS, Ni Y, Dennis PA (2001). Akt/protein kinase B is constitutively active in non-small cell lung cancer cells and promotes cellular survival and resistance to chemotherapy and radiation. Cancer Res, 61, 3986-97.

Daniel NN, Korsmeyer SJ (2004). Cell death: critical control points. Cell, 116, 205-19.

Evan GI, Vousden KH (2001). Proliferation, cell cycle and apoptosis in cancer. Nature, 411, 342.

Goldar S, Khaniani MS, Derakhshan SM, Baradaran B (2015). Molecular mechanisms of apoptosis and roles in cancer development and treatment. Asian Pac J Cancer Prev, 6, 2129-44.

Govindan R, Ding L, Griffith M, et al (2012). Genomic landscape of non-small cell lung cancer in smokers and never-smokers. Cell, 16, 1121-34.

Hahnvajanawong C, Wattanawongdon W, Chomvarin C, et al (2014). Synergistic effects of isomorellin and forbesione with doxorubicin on apoptosis induction in human cholangiocarcinoma cell lines. Cancer Cell Int, 14, 68.

Hata AN, Engelman JA, Faber AC (2015). The BCL2 family: key mediators of the apoptotic response to targeted anticancer therapeutics. Cancer Discov, 5, 475-87.

Hirsch FR, Bunn PA Jr, Johnson DH, Giaccone G, Rosell R (2003). Lung cancer. Introduction. Lung Cancer, 41, S1.

$\mathrm{Hu}$ Q, Wu D, Chen W, Yan Z, Shi Y (2013). Proteolytic processing of the caspase-9 zymogen is required for apoptosome-mediated activation of caspase-9.J Biol Chem, 288, $15142-7$.

Huang L, Fu L (2015). Mechanisms of resistance to EGFR tyrosine kinase inhibitors. Acta Pharm Sin B, 5, 390-401.

Janicke RU, Sprengart ML, Wati MR, Porter AG (1998). Caspase-3 is required for DNA fragmentation and morphological changes associated with apoptosis. J Biol Chem, 273, 9357-60.

Kanokmedhakul S, Lekphrom R, Kanokmedhakul K, et al (2012). Cytotoxic sesquiterpenes from luminescent mushroom Neonothopanus nambi. Tetrahedron, 68, 8261-6.
Khuri FR, Wu H, Lee JJ, et al (2001). Cyclooxygenase-2 overexpression is a marker of poor prognosis in stage I non-small cell lung cancer. Clin Cancer Res, 7, 861-7.

Khuri FR, Cohen V (2004). Molecularly targeted approaches to the chemoprevention of lung cancer. Clin Cancer Res, 10, 4249-53.

Li Q, Wei YQ, Wen YJ, et al (2004). Induction of apoptosis and tumor regression by vesicular stomatitis virus in the presence of gemcitabine in lung cancer. Int J Cancer, 112, 143-9.

Liang X, WuA, Xu Y, et al (2011). B1, a novel naphthalimide-based DNA intercalator, induces cell cycle arrest and apoptosis in HeLa cells via p53 activation. Inves New Drugs, 29, 646-58.

Martin S, Reutelingsperger CP, McGahon AJ, et al (1995). Early redistribution of plasma membrane phosphatidylserine is a general feature of apoptosis regardless of the initiating stimulus: inhibition by overexpression of $\mathrm{Bcl}-2$ and Abl. J Exp Med, 182, 1545-56.

Molina JR, Adjei AA, Jett JR (2006). Advances in chemotherapy of non-small cell lung cancer. Chest, 130, 1211-9.

Nicholson DW, Thornberry NA (1997). Caspases: killer proteases. Trends Biochem Sci, 22, 299- 306.

Pakzad R, Mohammadian-Hafshejani A, Ghoncheh M, Pakzad I, Salehiniya H (2015). The incidence and mortality of lung cancer and their relationship to development in Asia. Transl Lung Cancer Res, 4, 763-74.

Peng C, Sun M, Su J, Li Q (2016). Effect of gambogenic acid on inducing A549 cell apoptosis through regulating Ras/ Raf/Erk signaling pathway. Traditional Chin Drug Res Clin Plarmacol, 27, 189-93.

Raez LE, Lilenbaum R (2004). Chemotherapy for advanced non-small-cell lung cancer. Clin Adv Hematol Oncol, 2 , 173-8.

Reddy KB, Nabha SM, Atanaskova N (2003). Role of MAP kinase in tumor progression and invasion. Cancer Metastasis Rev, 22, 395-403.

Salomon DS, Brandt R, Ciardiello F, Normanno N (1995), Epidermal growth factor-related peptides and their receptors in human malignancies. Crit Rev Oncol Hematol, 19, 183-232.

Salvesen GS, Dixit VM (1997). Caspases: intracellular signalling by proteolysis. Cell, 91, 443-6.

Siegel R, Naishadham D, Jemal A (2013). Cancer statistics, 2013. CA Cancer J Clin, 63, 11-30.

Singhal S, Vachani A, Antin-Ozerkis D, Kaiser LR, Albelda SM (2005). Prognostic implications of the cell cycle, apoptosis, and angiogenesis biomarkers in non-small cell lung cancer: a review. Clin Cancer Res, 11, 3974-86.

Su J, Cheng H, Zhang D, et al (2014). Synergistic effects of 5 fluorouracil and gambogenic acid on A549 cells: Activation of cell death caused by apoptotic and necroptotic mechanisms via the ROS mitochondria pathway. Biol Pharm Bull, 37, 1259-68.

Torre LA, Bray F, Siegel RL, et al (2015). Global cancer statistics, 2012. CA Cancer J Clin, 65, 87-108.

Verbeek BS, Adriaansen-Slot SS, Vroom TM, Beckers T, Rijksen G (1998). Overexpression of EGFR and c-erbB2 causes enhanced cell migration in human breast cancer cells and NIH3T3 fibroblasts. FEBS Lett, 425, 145-50.

Woodburn JR (1999). The epidermal growth factor receptor and its inhibition in cancer therapy. Pharmacol Therapeut, 82, 241-50.

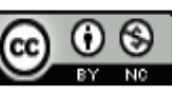

This work is licensed under a Creative Commons AttributionNon Commercial 4.0 International License. 